\title{
Neuropeptide $Y$ as a Biomarker and Therapeutic Target for Neuroblastoma
}

Susana Galli, ${ }^{*}$ Arlene Naranjo, ${ }^{\dagger}$ Collin Van Ryn,${ }^{\dagger}$ Jason U. Tilan, ${ }^{\ddagger \S}$ Emily Trinh, * Chao Yang, ${ }^{*}$ Jessica Tsuei, * Sung-Hyeok Hong, Hongkun Wang, "Ewa Izycka-Swieszewska, ${ }^{* *}$ Yi-Chien Lee, "Olga C. Rodriguez, "Chris Albanese, ${ }^{\top \dagger \dagger}$ and Joanna Kitlinska*

From the Department of Biochemistry and Molecular \& Cellular Biology,* the Department of Oncology, Lombardi Comprehensive Cancer Center, and the Departments of Biostatistics and Bioinformatics ${ }^{\|}$and Pathology, ${ }^{\dagger \dagger}$ Georgetown University Medical Center, Washington, District of Columbia; the Department of Biostatistics, ${ }^{\dagger}$ Children’s Oncology Group Statistics \& Data Center, University of Florida, Gainesville, Florida; the Department of Nursing ${ }^{\ddagger}$ and Department of Human Science, ${ }^{\S}$ School of Nursing and Health Studies, Georgetown University, Washington, District of Columbia; and the Department of Pathology and Neuropathology, ** Medical University of Gdańsk, Gdańsk, Poland

\author{
Accepted for publication \\ July 11, 2016. \\ Address correspondence to \\ Joanna Kitlinska, Ph.D., \\ 3900 Reservoir Rd. N.W., \\ Basic Science Bldg., Rm. \\ 231A, Washington, \\ DC 20057. E-mail: jbk4@ \\ georgetown.edu.
}

\begin{abstract}
Neuroblastoma (NB) is a pediatric malignant neoplasm of sympathoadrenal origin. Challenges in its management include stratification of this heterogeneous disease and a lack of both adequate treatments for high-risk patients and noninvasive biomarkers of disease progression. Our previous studies have identified neuropeptide $Y$ (NPY), a sympathetic neurotransmitter expressed in NB, as a potential therapeutic target for these tumors by virtue of its $\mathrm{Y}_{5}$ receptor ( $\left.\mathrm{Y} 5 \mathrm{R}\right)$-mediated chemoresistance and $\mathrm{Y} 2$ receptor (Y2R)-mediated proliferative and angiogenic activities. The goal of this study was to determine the clinical relevance and utility of these findings. Expression of NPY and its receptors was evaluated in corresponding samples of tumor RNA, tissues, and sera from 87 patients with neuroblastic tumors and in tumor tissues from the TH-MYCN NB mouse model. Elevated serum NPY levels correlated with an adverse clinical presentation, poor survival, metastasis, and relapse, whereas strong Y5R immunoreactivity was a marker of angioinvasive tumor cells. In NB tissues from TH-MYCN mice, high immunoreactivity of both NPY and Y5R marked angioinvasive NB cells. Y2R was uniformly expressed in undifferentiated tumor cells, which supports its previously reported role in NB cell proliferation. Our findings validate NPY as a therapeutic target for advanced NB and implicate the NPY/Y5R axis in disease dissemination. The correlation between elevated systemic NPY and NB progression identifies serum NPY as a novel NB biomarker. (Am J Pathol 2016, 186: 3040-3053; http://dx.doi.org/10.1016/j.ajpath.2016.07.019)
\end{abstract}

Neuroblastoma (NB) is a pediatric malignant neoplasm that originates from precursors of sympathetic neurons. Clinical phenotypes of the disease range from spontaneously regressing to aggressive, metastatic neoplasms. ${ }^{1}$ Consequently, treatment regimens depend on the risk assignment and range from observation and surgery to intensive chemotherapy with irradiation. ${ }^{1}$ Recently, novel strategies that target basal neurobiological features of NB (eg, retinoic acid treatment) have improved its outcome. Nevertheless, the 5-year event-free survival (EFS) for patients with highrisk NB remains below $50 \%$. $^{2}$ Thus, treatment of aggressive tumors is a significant problem in NB management.

NB belongs to a larger group of neuroblastic tumors, which vary in their level of differentiation, with tumor cells ranging from undifferentiated and maturing neuroblasts to mature ganglion cells. ${ }^{3,4}$ On the basis of the level of neuronal differentiation and Schwannian stroma content, neuroblastic tumors are histologically classified as ganglioneuromas (GNs), which contain only mature ganglion cells, ganglioneuroblastomas (GNBs), which are composed of mature ganglion cells and neuroblasts, and NBs, which are entirely composed of neuroblasts. NBs are further subclassified according to their maturation stages into differentiating, poorly differentiated, and undifferentiated tumors, with the last group carrying the worst prognosis. ${ }^{3}$

Supported by NIH grants UL1TR000101 (previously UL1RR031975), 1RO1CA123211 (J.K.), 1R03CA178809 (J.K.), 1R01CA197964 (J.K.), 1R21CA198698 (J.K.), U10CA180899, and P30-CA051008.

Disclosures: None declared. 
Because of the extreme heterogeneity of $\mathrm{NB}$, its risk stratification is both important and challenging. Although MYCN amplification present in $16 \%$ to $25 \%$ of NB cases serves as one of the most powerful adverse prognostic indicators, the risk assessment for patients without this amplification is more complex. ${ }^{2}$ Currently, the most reliable NB stratification system developed by the International Neuroblastoma Risk Group (INRG) relies on a combination of multiple prognostic factors. ${ }^{2}$ However, patients with similar clinical parameters often present with different outcomes. ${ }^{5}$ Thus, novel factors have been proposed based on the molecular profiling of tumors. ${ }^{6-9}$ Although these new approaches carry a significant prognostic value, they rely on complex genetic methods, which are difficult to use in routine clinical practice. Moreover, both current and proposed stratification systems require access to tumor tissue, which is often limited, particularly in relapsing tumors. Therefore, there is a need for prognostic factors using easily accessible material, such as blood. Such circulating biomarkers may also improve disease monitoring, which currently relies on complex radioimaging and bone marrow aspirates. Although several of such blood biomarkers have been proposed, none have proven effective as a single prognostic indicator in NB risk stratification. ${ }^{2,10-12}$

Neuropeptide Y (NPY) is a sympathetic neurotransmitter that acts by binding to multiple receptors, designated $\mathrm{Y} 1$ receptor (Y1R) to Y5 receptor (Y5R). ${ }^{13}$ Our group and others have established that NPY regulates a variety of processes that are highly relevant to tumor biology, including cell proliferation, survival, differentiation, and motility. ${ }^{14-20}$ We have also found that NPY, acting via Y2R expressed in endothelial cells, stimulates angiogenesis under various pathologic conditions, including vascularization of solid tumors. ${ }^{16,20-23}$ Consequently, NPY has been implicated as a growth-promoting factor in several malignant tumors. ${ }^{24-27}$

Our previous investigations have found that NB cells synthesize and release NPY, consistent with their sympathetic origin. ${ }^{16,22}$ Early reports from other laboratories indicate that such a release results in elevated systemic NPY levels in NB patients and suggest its possible association with advanced disease and poor clinical outcome. ${ }^{28-30}$ However, the small patient cohorts analyzed did not allow for reliable survival analyses. Moreover, a potential association between serum NPY levels and tumor tissue expression of the peptide and its receptors has not been explored. Therefore, the role of NPY in NB biology and the significance of its elevated systemic levels remain unclear.

High NPY expression has also been reported in another sympathoadrenal tumor: pheochromocytoma. ${ }^{31-33}$ However, the studies on associations between disease malignancy and NPY levels in pheochromocytoma are contradictory. Although NPY mRNA was detected preferentially in benign tumors, its plasma levels were particularly high in patients with malignant pheochromocytoma. ${ }^{32,33}$ Interestingly, we found similar increases in circulating levels of NPY in patients with Ewing sarcoma, in whom the EWS-FLI1 fusion protein induces NPY expression. ${ }^{34}$ Although our cohort of individuals with metastatic Ewing sarcoma was limited, we observed a trend toward increased serum NPY levels in this group of patients compared with those with localized tumors.

In addition to NPY synthesis and release, NB cells also express NPY receptors. ${ }^{16} \mathrm{We}$ found that Y2R is constitutively expressed in NB cells and is essential for their proliferation and tumor vascularization, whereas $\mathrm{Y} 5 \mathrm{R}$ is induced in NB cells in proapoptotic conditions, such as chemotherapy, and promotes their survival and drug resistance. ${ }^{22,35}$ Importantly, we have established that blocking each of these receptors inhibits NB tumor growth in animal models. ${ }^{22,35}$ Thus, our previous studies have clearly established a central role of the NPY axis in NB biology. However, clinical data validating the relevance of these findings and identifying a population of NB patients who could benefit from anti-NPY therapies is lacking.

In the current study, we investigated the pattern of NPY system expression across the spectrum of human neuroblastic tumors to determine whether its elevated levels correlated with specific disease phenotypes. Our results, collected from 87 pediatric patients, revealed that high serum NPY levels were associated with unfavorable prognostic factors and poor survival in NB patients. Moreover, elevated circulating NPY was correlated with both metastatic disease and future relapse. Finally, high Y5R immunoreactivity was observed in NB cells with an angioinvasive phenotype, implicating the $\mathrm{NPY} / \mathrm{Y} 5 \mathrm{R}$ axis in NB metastasis. In contrast, Y2R was present in most NB cells and in the tumor vasculature, consistent with its essential role in maintaining NB growth and vascularization. Together, our results validate the NPY axis as a relevant therapeutic target in NB and support the measurement of NPY serum levels as a minimally invasive tool for both risk stratification and disease monitoring.

\section{Materials and Methods}

\section{Human Samples}

Matching samples of primary tumor mRNA, paraffinembedded tissue sections, and serum from 87 pediatric patients with neuroblastic tumors at diagnosis, collected from 2004 to 2009, were obtained from the Children's Oncology Group (COG) (Table 1). These samples were collected by COG institutions upon obtaining appropriate consents, and their use was approved by the Georgetown University Institutional Review Board.

\section{Real-Time RT-PCR}

cDNA was synthesized using an iScript cDNA Synthesis Kit and amplified using the ICycler iQ Detection System (BioRad Laboratories, Hercules, CA), TaqMan Universal PCR Master Mix (Applied Biosystems, Foster City, CA), and predesigned primers and fluorescein-labeled probes (Applied 
Table 1 Patient Demographic Characteristics

\begin{tabular}{ll}
\hline Characteristic & Finding $(n=87)$ \\
\hline Sex & \\
Male & $47(54)$ \\
Female & $40(46)$ \\
Age at diagnosis & \\
$\quad$ Median (range) & 1.5 years (6 days-13.1 years) \\
$\quad<18$ months & $44(51)$ \\
$\geq 18$ months & $43(49)$ \\
Race & \\
Asian & $3(3)$ \\
Native Hawaiian or other & $2(2)$ \\
$\quad$ Pacific Islander & $11(13)$ \\
Black or African American & $60(69)$ \\
White & $11(13)$ \\
Unknown or not reported & \\
Ethnicity & $69(79)$ \\
Not Hispanic or Latino & $15(17)$ \\
Hispanic or Latino & $3(3)$ \\
Unknown &
\end{tabular}

Data are presented as $n(\%)$ of patients unless otherwise indicated.

Biosystems). The results were calculated by the comparative $\mathrm{C}_{\mathrm{T}}$ method using $\beta$-actin as a reference gene. For each sample, the $\Delta \mathrm{C}_{\mathrm{T}}$ value was calculated as a difference between threshold cycles for the gene of interest and $\beta$-actin and then converted into the fold increase over $\beta$-actin according to the formula $2^{-\Delta \mathrm{CT}}$. These values were then compared among samples in the experimental groups. The RNA samples with $\mathrm{C}_{\mathrm{T}}$ values for $\beta$-actin exceeding 30 were considered degraded and excluded from analysis. Thus, among 87 RNA samples tested, 83 were suitable for analysis.

\section{Tissue Analysis}

Histologic grade was assessed according to the International Neuroblastoma Pathology Classification. ${ }^{4}$ Immunohistochemistry was performed using rabbit polyclonal antibodies: anti-NPY (1:1000) (Sigma, St. Louis, MO), anti-Y5R (1:300) (Novus Biologicals, Littleton, CO), and anti-Y2R (1:25) (Abcam, Cambridge, MA). The percentage of cells positive for particular proteins in the fractions of undifferentiated and differentiating tumor cells was assessed independently by two pathologists (S.G. and E.I.). Moreover, quantification of $\mathrm{Y} 5 \mathrm{R}$ staining intensities in tumor cells distant from the vasculature and those directly surrounding the vessels was performed using Image J version $1.45 \mathrm{~s}(\mathrm{NIH}$, Bethesda, MD; http://imagej.nih.gov/ij). One of 87 tissue samples was entirely composed of necrotic tissue and thus was excluded from analyses as nonevaluable.

\section{NPY ELISA}

Serum NPY concentrations were measured by enzymelinked immunosorbent assay (ELISA) (Bachem Peninsula Laboratories, San Carlos, CA), as previously described. ${ }^{34}$
Four of 87 serum samples had an insufficient volume for ELISA assay and therefore were excluded from analyses.

\section{Animal Model}

$129 \mathrm{X} 1 / \mathrm{SvJ}$ mice expressing the human MYCN oncogene under a rat tyrosine hydroxylase promoter (TH-MYCN mice) were obtained from the National Cancer Institute (Frederick, MD) ${ }^{36} \mathrm{NB}$ tumor progression was monitored by magnetic resonance imaging (MRI) in the Georgetown University Lombardi Comprehensive Cancer Center Preclinical Imaging Research Laboratory in a 7.0-T horizontal Bruker magnet run by Paravision version 5.1 (Bruker, Billerica, MA). For imaging, mice were placed on a custommade stereotaxic holder (ASI Instruments, Warren, MI) and imaged with a 40-mm Bruker mouse body coil. The MRI sequence used was a two-dimensional T2-weighted RARE protocol previously described. ${ }^{37}$

\section{Statistical Analysis}

Patients were stratified according to prognostic factors: age ( $<18$ vs $\geq 18$ months), stage by the International Neuroblastoma Staging System (nonstage 4 vs stage 4), grade (undifferentiated or poorly differentiated vs differentiating), mitosis-karyorrhexis index (MKI, low or intermediate vs high), histologic findings (favorable vs unfavorable), $M Y C N$ status (nonamplified vs amplified), ploidy (hyperdiploid vs diploid), risk by INRG (low/intermediate vs high), and metastatic disease (stages 1 to 3 vs 4 and 4 S). ${ }^{2}$ Clinical information for some patients in our cohort was partially missing: grade (4 patients), MKI (7 patients), ploidy (2 patients), histologic findings (4 patients), and MYCN amplification status (1 patient). These patients were excluded from the particular analyses. Recurrence was defined as relapse or progression, excluding death as the first event. There were 7 deaths as first events, and these patients were excluded from recurrence analysis.

In addition, patients were categorized as having low (below median) or high (above median) levels of NPY or its receptor expression, as measured by real-time RT-PCR, immunohistochemistry, and NPY serum concentrations. For each of the categorical prognostic variables, a Wilcoxon rank sum or Fisher exact test was administered to compare NPY and receptor values, and a log rank test was performed to compare EFS and overall survival (OS) between groups. EFS and OS were calculated using the Kaplan-Meier method ${ }^{38}$ with SEs per Peto et al. ${ }^{39}$ For EFS, an event was defined as relapse, progression, secondary malignant neoplasm, or death from any cause. For OS, death was the only event considered. Time to event or death was calculated from the date of diagnosis. In the absence of an event or death, the survival time was censored at the time of last contact. Multivariate Cox proportional hazard models were fit to explore the effect of the serum NPY levels on EFS and OS when adjusting for other covariates. 
On the basis of the exploratory nature of the analysis, no multiple test adjustment procedure was adopted, and $P<$ 0.05 was considered statistically significant. To avoid experimental bias, the analytical procedures and initial data analyses were performed at Georgetown University, whereas the clinical data were available only to the COG biostatisticians who performed subsequent statistical tests (A.N. and C.V.R.).

\section{Results}

\section{Elevated Serum NPY Levels in Patients with Undifferentiated or Poorly Differentiated NBs}

Of the 87 samples tested in our cohort of neuroblastic tumors, 80 were NBs (45 undifferentiated, 24 poorly differentiated, and 11 differentiating), 5 were GNBs, and 2 were GNs. NPY mRNA and protein were detectable in all tested tumor tissues. The median serum NPY level among patients with neuroblastic tumors was $0.69 \mathrm{ng} / \mathrm{mL}$ (Figure 1A), which was equal to the maximum serum NPY concentration in healthy pediatric controls using the same method (ELISA) ${ }^{34}$ Therefore, to determine whether a high serum NPY level correlated with a specific disease phenotype, we used a median serum concentration of $0.69 \mathrm{ng} / \mathrm{mL}$ as the cutoff point to stratify patients into low (below median levels) and high (at or above median) systemic NPY categories.

Because expression of NPY reflects neuronal features of $\mathrm{NB}$, we first assessed whether its tumor mRNA and systemic levels depend on the stage of tumor differentiation. Serum NPY was elevated in patients with undifferentiated and poorly differentiated NBs (median, $0.75 \mathrm{ng} / \mathrm{mL}$ ), whereas those with differentiating tumors had a median concentration of $0.35 \mathrm{ng} / \mathrm{mL}$, which is comparable to healthy pediatric controls (median, $0.5 \mathrm{ng} / \mathrm{mL}$ )
A
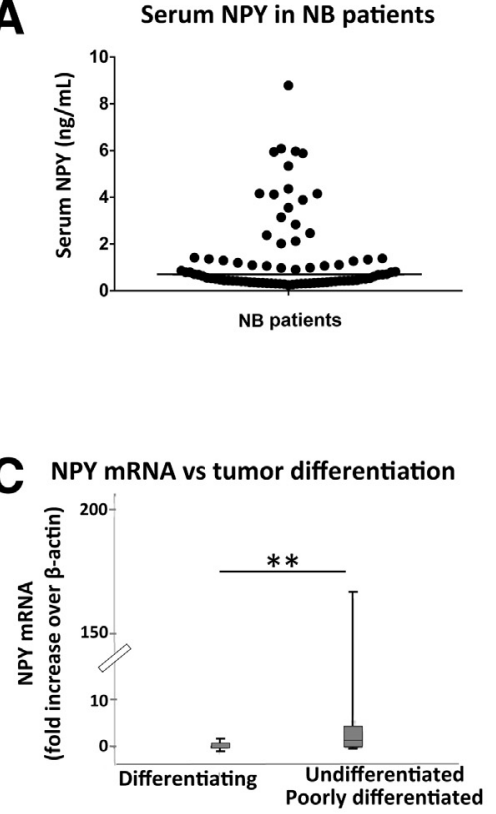

C NPY mRnA vs tumor differentiation
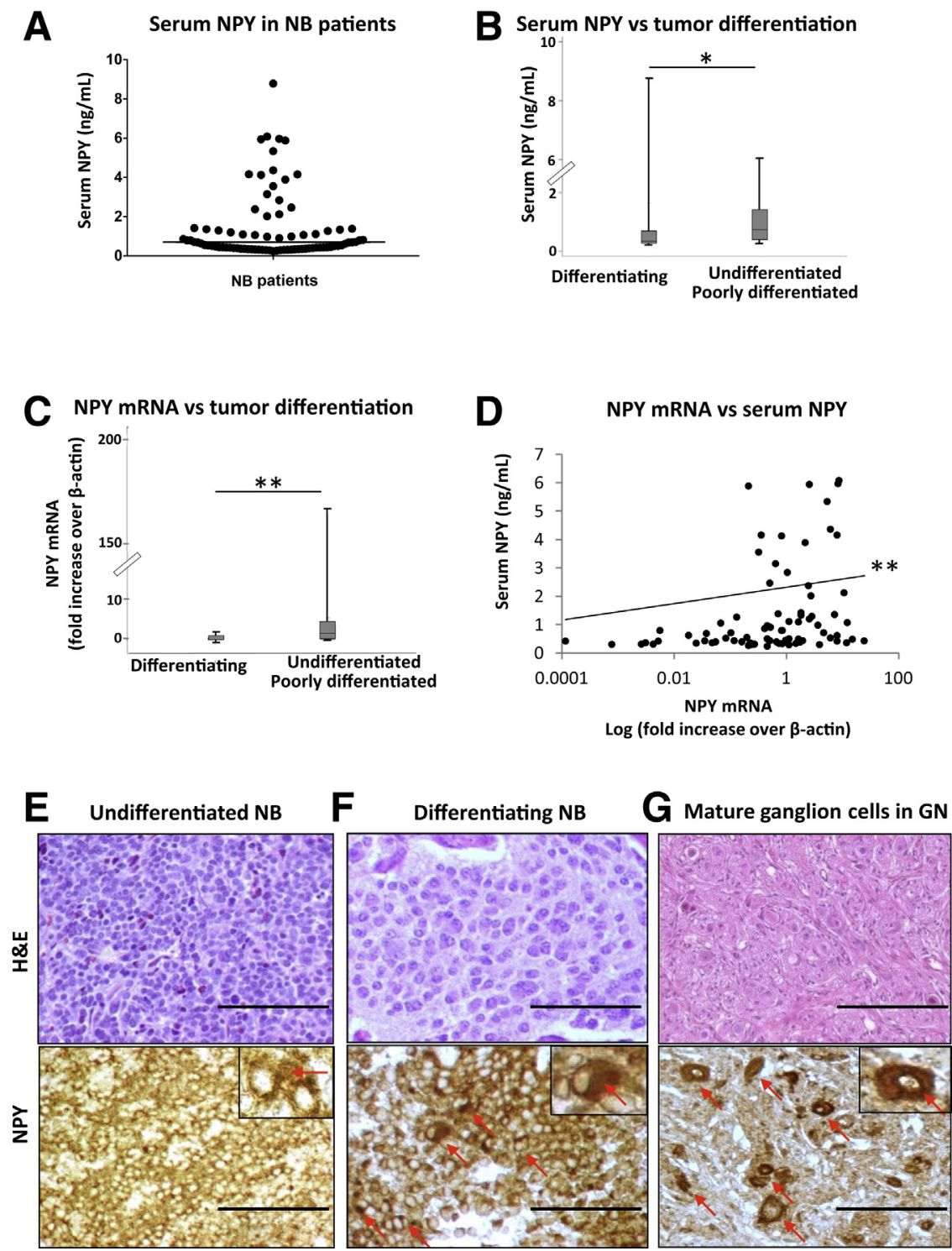

Figure 1 Undifferentiated neuroblastoma (NB) tumors synthesize and release high levels of neuropeptide Y (NPY). A: Variability in serum NPY concentrations, measured by enzyme-linked immunosorbent assay, among patients with neuroblastic tumors. The solid line represents the median NPY level $(0.69 \mathrm{ng} / \mathrm{mL})$. B: Elevated serum NPY levels in patients with undifferentiated or poorly differentiated tumors (median, 0.75 $\mathrm{ng} / \mathrm{mL}$ ) compared with those with differentiating tumors (median, $0.35 \mathrm{ng} / \mathrm{mL}$ ). C: NPY mRNA levels, measured by real-time RT-PCR, are significantly higher in tissues from undifferentiated or poorly differentiated tumors compared with differentiating NBs. D: In patients with neuroblastic tumors, serum NPY concentrations positively correlate with its tumor mRNA levels. The statistical analysis was performed on $\Delta C_{T}$ values $(r=-0.3215)$; however, the mRNA levels shown on the graph were converted to fold increase over $\beta$-actin according to the formula $2^{-\Delta C T}$ to illustrate the positive direction of the correlation. EG: Representative micrographs of NB tissues at different grades of histological differentiation stained with hematoxylin and eosin (H\&E, top row) and anti-NPY antibody (NPY, bottom row). In undifferentiated tumors, a significant amount of NPY is detectable in extracellular spaces and at the cytoplasmic level $(\mathbf{E})$, whereas maturing cells in differentiating NBs $(\mathbf{F})$ and mature ganglion cells in ganglioneuromas (GNs) (G) accumulate NPY in the cytoplasm (red arrows). Data are presented as box plots representing range (vertical lines), 25th and 75th percentile (bottom and top of the box, respectively), and median value (solid horizontal line within the box) (B and C). $n=83$ (A); $n=68$ (B, undifferentiated or poorly differentiated tumors); $n=11$ (B, differentiating tumors); $n=69$ (C, undifferentiated or poorly differentiated tumors); $n=10$ (C, differentiating NBs) $; n=79$ (D). ${ }^{*} P<0.05,{ }^{*} P<0.01$. Scale bar $=200 \mu \mathrm{m}$. Original magnification: $\times 200$ (E-G, main images); $\times 400$ (insets). H\&E, hematoxylin and eosin. 
(Figure 1B). ${ }^{34}$ The patients with undifferentiated or poorly differentiated NBs also had significantly higher NPY mRNA levels compared with the differentiating tumors (Figure 1C). Accordingly, 56\% of patients with undifferentiated or poorly differentiated NBs had tumor NPY mRNA levels above the median, whereas none of the cases with differentiating tumors reached this level (Table 2). In line with these findings, we observed a positive correlation between the NPY mRNA and serum levels in the entire cohort of patients with neuroblastic tumors $(P<0.01)$ (Figure 1D), although this association was the most significant in the subgroup with undifferentiated tumors $(P<0.001)$.

Similar to its mRNA and serum levels, the NPY immunostaining pattern varied among different histologic tumor types. Undifferentiated or poorly differentiated NBs exhibited marked amounts of NPY detectable at the cytoplasmic level and in extracellular spaces (Figure 1E), whereas in differentiating NBs NPY was mainly localized in the cytoplasmic compartments of neuroblastic and maturing cells (Figure 1F). Similar strong intracellular staining was observed in mature ganglion cells of GNBs and GNs (Figure 1G). Collectively, these data suggest that elevated NPY expression observed in undifferentiated or poorly differentiated tumors leads to its release to the extracellular space and subsequently to the circulation, whereas these processes are diminished in differentiating tumors. No significant associations between the percentage of NPYpositive cells assessed by immunostaining and NB prognostic factors were observed.

Table 2 Associations of Tumor NPY mRNA and Its Serum Protein Levels with Neuroblastoma Prognostic Factors

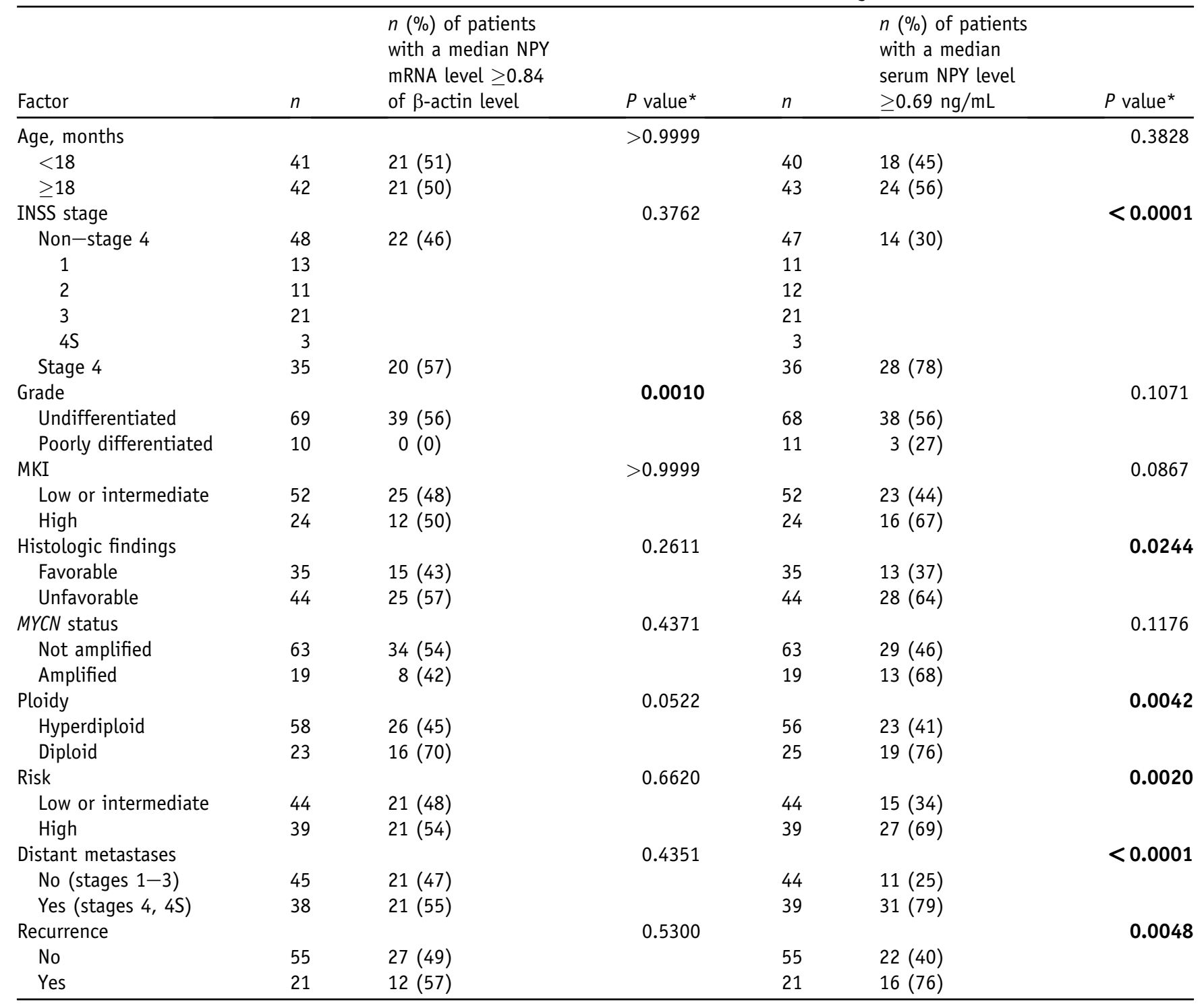

*Statistically significant differences $(P<0.05)$ are in bold.

INSS, International Neuroblastoma Staging System; MKI, mitosis-karyorrhexis index; NPY, neuropeptide Y. 

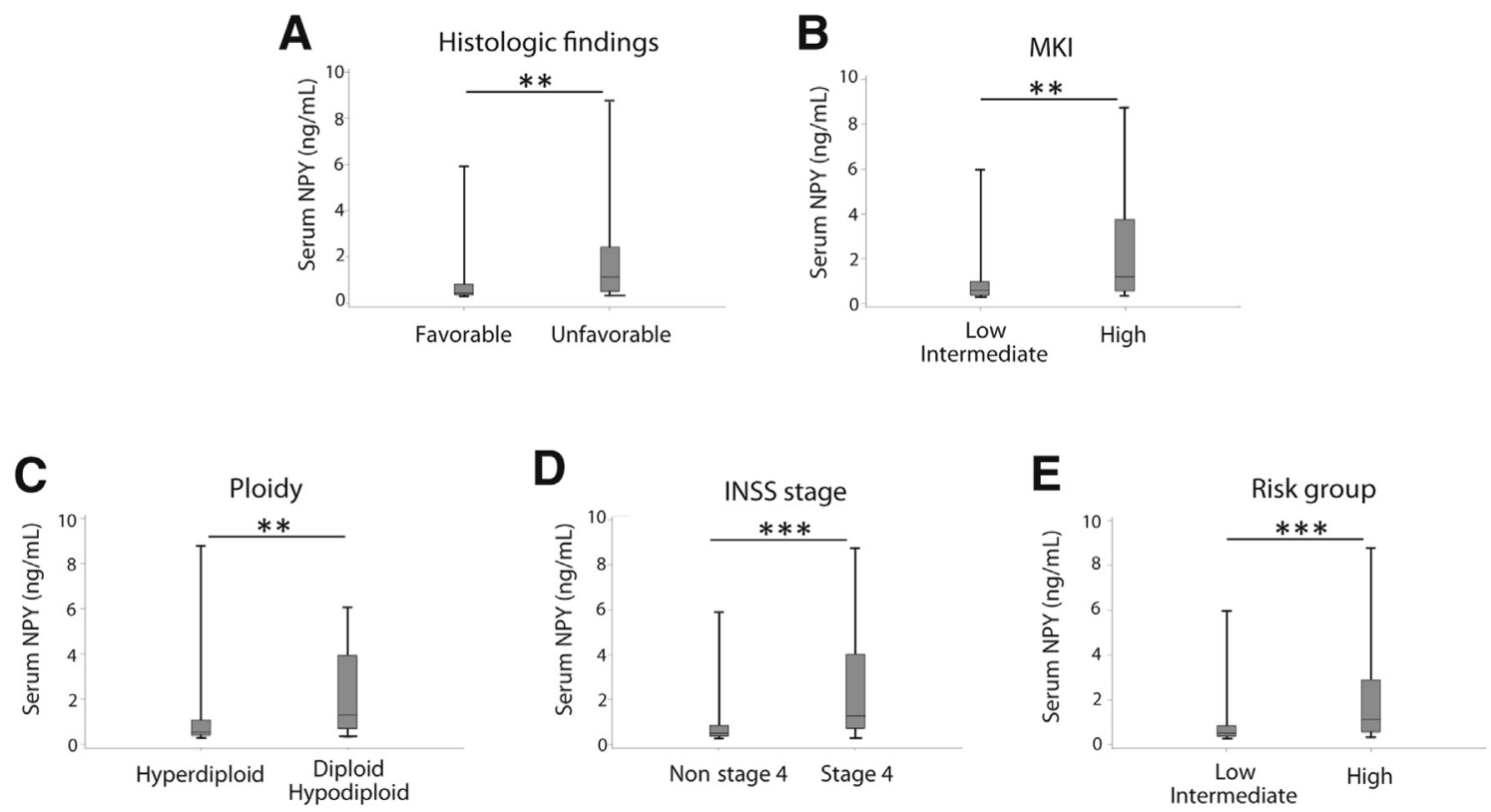

Figure 2 Elevated circulating neuropeptide Y (NPY) levels correlate with established adverse neuroblastoma (NB) prognostic factors. Serum NPY levels, measured by enzyme-linked immunosorbent assay, are significantly elevated in NB patients with unfavorable disease phenotype characterized by the following. A: Unfavorable histologic features (median, 0.44 and $1.06 \mathrm{ng} / \mathrm{mL}$ for patients with favorable and unfavorable histologic findings, respectively). B: High mitosis-karyorrhexis index (MKI) (median, 0.50 and $1.16 \mathrm{ng} / \mathrm{mL}$ for patients with low or intermediate and high MKI, respectively). C: Near diploid karyotype (median, 0.52 and $1.27 \mathrm{ng} / \mathrm{mL}$ for patients with hyperdiploid and diploid karyotype, respectively). D: High stage of disease, based on the International Neuroblastoma Staging System (INSS) (median, 0.44 and $1.24 \mathrm{ng} / \mathrm{mL}$ for patients with non-stage 4 tumors and patients with stage 4 disease). E: High risk, based on the International Neuroblastoma Risk Group classification (median, $0.45 \mathrm{ng} / \mathrm{mL}$ and $1.1 \mathrm{ng} / \mathrm{mL}$ for patients with low- or intermediate- and high-risk disease, respectively). Data are presented as box plots representing range (vertical lines), 25th and 75th percentile (bottom and top of the box, respectively), and median value (solid horizontal line within the box). $n=35$ (A, favorable histologic findings); $n=45$ (A, unfavorable histologic findings); $n=52$ (B, low or intermediate MKI); $n=24$ (B, high MKI); $n=56$ (C, hyperdiploid karyotype); $n=25$ (C, diploid karyotype); $n=47$ (D, non-stage 4 tumors); $n=36$ (D, stage 4 disease); $n=44$ (E, low- or intermediate-risk disease); $n=39$ (E, high-risk disease). ${ }^{* * P}<0.01,{ }^{* *} P<0.001$.

\section{Association of High Serum NPY Levels with Unfavorable Prognosis}

To assess potential associations of elevated systemic NPY levels with NB clinical presentation and outcome, we compared systemic NPY levels in patients with different clinical features of the disease. Serum NPY levels were significantly elevated in patients with tumors characterized by several established adverse prognostic features, including unfavorable histologic findings, a high MKI and a near diploid karyotype, and stage 4 and high-risk disease based on INRG risk classification (Figure 2). ${ }^{2}$ Conversely, patients with a favorable disease presentation and low-risk tumors had NPY concentrations comparable to those previously reported for healthy children (median, $0.5 \mathrm{ng} / \mathrm{mL}$ ). ${ }^{34}$ Consequently, serum NPY concentrations above the median level in our cohort $(0.69 \mathrm{ng} /$ $\mathrm{mL}$ ) were more often observed in patients with adverse prognostic features and significantly correlated with stage 4 (78\% of patients with elevated NPY levels), diploid karyotype (76\% of patients), and high-risk disease $(69 \%$ of patients) (Table 2).

This strong association of elevated systemic NPY with an unfavorable clinical phenotype of NB was in agreement with significantly worse EFS and OS in patients with serum
NPY levels above the median $(P<0.05)$ (Figure 3A). For patients with high and low serum NPY levels, the 5-year EFS rates \pm SE were $48.7 \% \pm 9.0 \%$ vs. $80.3 \% \pm 8.6 \%$ and the 5-year OS rates were \pm SE $58.2 \% \pm 8.9 \%$ vs. $86.5 \% \pm 7.3 \%$, respectively. Strikingly, the most significant association between high serum NPY levels and poor survival occurred in the subpopulation of patients with stage 1 to 4 tumors without $M Y C N$ amplification $(P<0.01)$ (Figure 3B). In this subgroup, the 5-year EFS rates \pm SE were $49.7 \% \pm 11.7 \%$ versus $88.9 \% \pm 7.9 \%$, and the 5 -year OS rates $\pm \mathrm{SE}$ were $56.3 \% \pm 11.8 \%$ versus $96.7 \% \pm 4.4 \%$ for patients with high and low serum NPY, respectively. In contrast, no such correlations were observed in the cohort with MYCN amplification $(P=0.9$ and $P=0.8$ for EFS and OS, respectively; data not shown), although serum NPY levels remained high in this group (median, $1.07 \mathrm{ng} / \mathrm{mL}$ ). Similarly, no difference in the survival of patients with high and low serum NPY levels was observed within a high-risk disease subgroup, as defined by INRG criteria $(P=0.8$ and $P=0.9$ for EFS and OS survival, respectively; data not shown). Importantly, however, $49 \%$ of patients in this subgroup had $M Y C N$-amplified tumors. In contrast, there was a noticeable trend toward worse survival in patients with high NPY levels within a subpopulation with low- or 


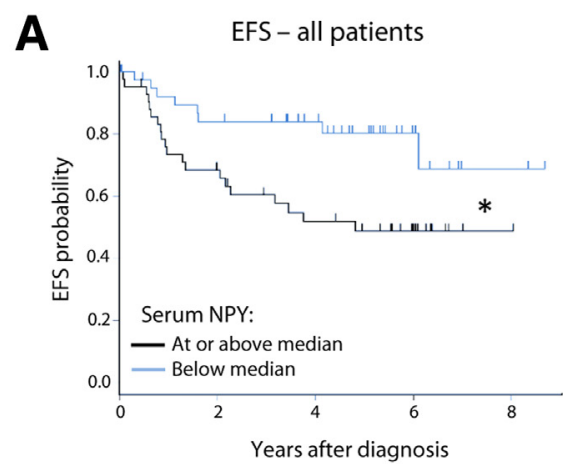

B
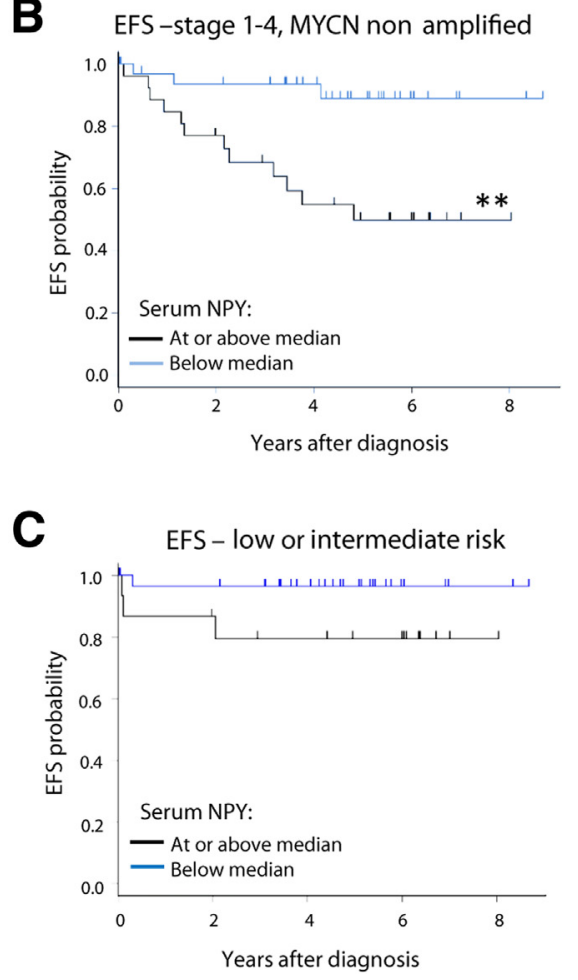
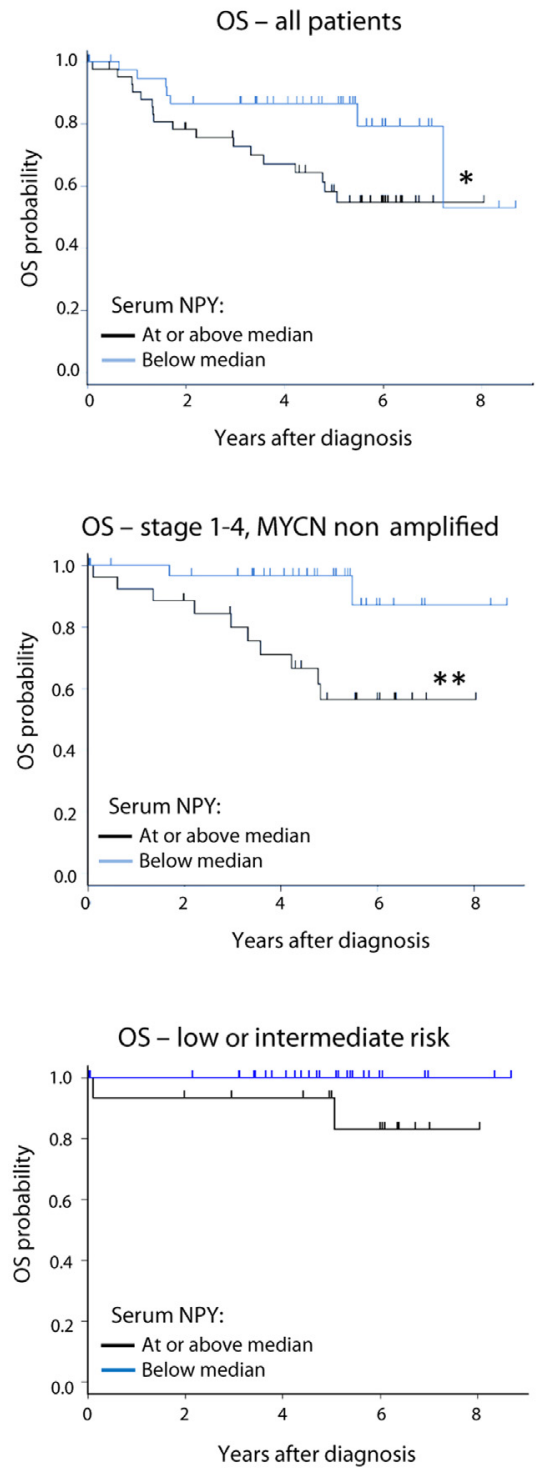

Figure 3 High systemic neuropeptide Y (NPY) correlates with worse neuroblastoma (NB) patient survival. A: Comparison of event-free survival (EFS; left graph) and overall survival (OS; right graph) in patients with low serum NPY concentrations (below the median level of $0.69 \mathrm{ng} / \mathrm{mL}$ ) and high serum NPY concentrations (at or above the median level). These analyses were performed on the entire experimental cohort. B: Similar survival analyses performed on a subpopulation of patients with stage 1 to 4 (non-stage 4S), MYCN-nonamplified tumors. C: Comparison of EFS and OS in patients with low and high NPY concentrations performed in a subpopulation of patients with lowto intermediate-risk disease. $n=41$ (A, low serum NPY concentrations); $n=42$ (A, high serum NPY concentrations); $n=26$ (B, high NPY concentrations); $n=34$ (B, low NPY concentrations); $n=$ 29 (C, low NPY concentrations); $n=15$ (C, high NPY concentrations). ${ }^{*} P<0.05,{ }^{*} P<0.01$. intermediate-risk disease by INRG, which do not carry $M Y C N$ amplification, although these differences did not achieve statistical significance $(P=0.08$ and $P=0.07$ for EFS and OS, respectively) (Figure $3 \mathrm{C}$ ). ${ }^{2}$

Despite the strong association of serum NPY with worse survival in univariate analysis, when adjusted for the effects of stage by International Neuroblastoma Staging System and histologic features in the multivariate Cox proportional hazards model, serum NPY did not achieve statistical significance as an independent prognostic factor (data not shown). This lack of significance was primarily attributable to the strong correlation of elevated levels of systemic NPY with these two covariates (stage 4, $P<0.0001$, and unfavorable histologic features, $P=0.02$ ) (Table 2). Strikingly, in the same multivariate analysis, MYCN amplification also failed to achieve statistical significance for EFS, despite its well-established prognostic value.

\section{Association of Elevated Serum NPY Levels at Diagnosis with Metastatic Disease and Future Relapse}

We next correlated patients' serum NPY levels with the presence or absence of distant metastases. In line with its adverse effect on patient survival, serum NPY levels were significantly elevated in patients with metastatic disease at diagnosis compared with those without known metastases $(P<0.0001)$ (Figure 4A). Consequently, serum NPY levels above the median were observed in $79 \%$ of patients with distant metastases compared with $25 \%$ of those with localized tumors $(P<0.0001)$ (Table 2$)$. Similarly, patients who experienced relapse during the disease were significantly more likely to have serum NPY levels at diagnosis above the median compared with patients without relapse (76\% vs $40 \% ; P=0.005$ ) (Table 2). In addition, there was a statistically significant difference in median serum NPY levels between these two groups $(P=0.029)$ (Figure 4A). 
A

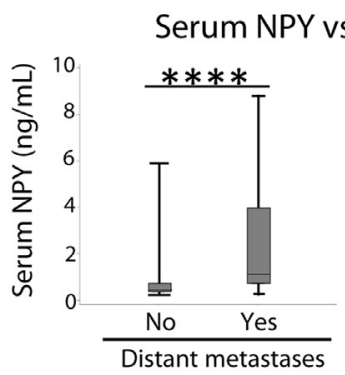

\section{B Differentiating human NB}

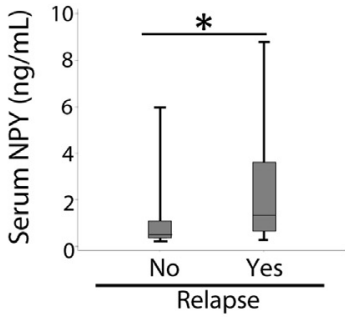

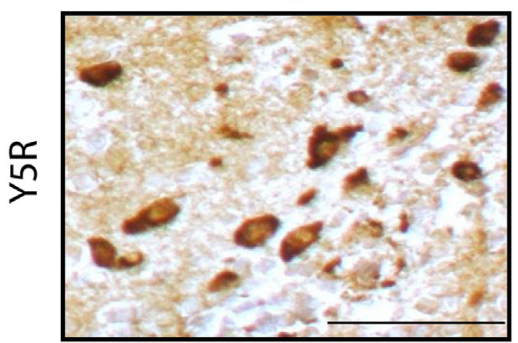

Undifferentiated human NBs

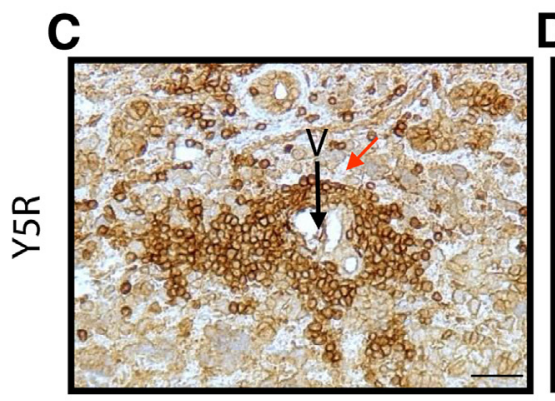

D

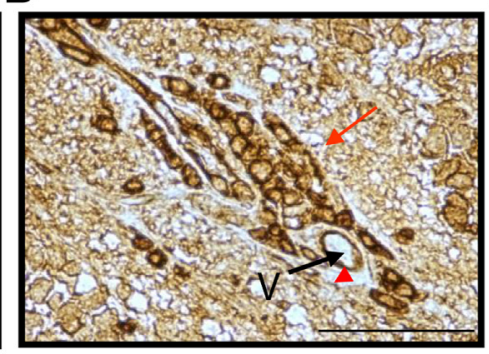

E

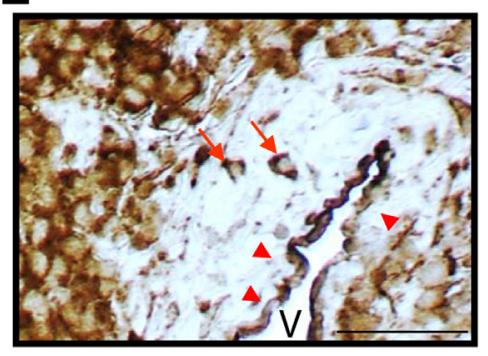

H

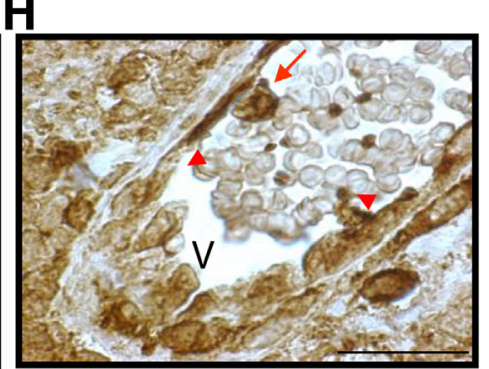

Figure 4 Elevated circulating neuropeptide Y (NPY) and high Y5 receptor (Y5R) expression are associated with neuroblastoma (NB) dissemination and an invasive phenotype. A: Serum NPY concentration are elevated in patients with metastases at diagnosis (median, 0.44 and $1.11 \mathrm{ng} / \mathrm{mL}$ for patients with localized disease and distant metastases, respectively) and future relapse (median, 0.50 and $1.34 \mathrm{ng} / \mathrm{mL}$ for patients without disease recurrence and with relapse, respectively). B: A representative image of Y5R immunostaining (brown) in differentiating human NB. C-H: Representative micrographs of Y5R immunostaining in undifferentiated human NB cells with angioinvasive characteristics. C and D: Groups of Y5R-positive NB cells or isolated tumor cells accumulate in close proximity to blood vessels and align along them. E and F: Y5R-positive cells penetrate the vessel wall. G: A Y5R-positive cell with a morphologic deformation that is characteristic of the intravasating tumor cells. H: The Y5R-positive cells are also detectable in the vessel lumen. Red arrows indicate Y5R-positive tumor cells, whereas red arrowheads indicate Y5R-positive endothelial cells. Data are presented as box plots representing range (vertical lines), 25th and 75th percentile (bottom and top of the box, respectively), and median value (solid horizontal line within the box) (A). $n=44$ (A, localized disease); $n=39$ (A, distant metastases); $n=55$ (A, no relapse); $n=21$ (A, relapse). ${ }^{*} P<0.05,{ }^{*} * * P<0.0001$. Scale bars: $100 \mu \mathrm{m}(\mathbf{B}) ; 50 \mu \mathrm{m}(\mathbf{C}-\mathbf{H})$. V, blood vessel.

\section{Expression of Y5R in Angioinvasive NB Cells}

To define the possible mechanisms of NPY's adverse effects on NB patient survival, we investigated the expression patterns of NPY receptors across tumor subtypes. On the basis of our previous studies, we focused on Y2R and Y5R because these two receptors play essential roles in NB biology. ${ }^{16,22,35}$ No associations between Y5R expression level, as measured by RT-PCR or a percentage of Y5Rimmunoreactive cells, and NB prognostic factors were observed. However, we identified a specific pattern of Y5R expression in NB tissues. Although Y5R immunostaining was detected at cytoplasmic and membrane levels in maturing ganglion cells (Figure 4B) and undifferentiated neuroblasts (Figure 4, C-H), its expression in undifferentiated or poorly differentiated NBs was particularly high in an apparently invasive subset of tumor cells. Specifically, high Y5R expression was observed in isolated tumor cells or their clusters that accumulated immediately adjacent to blood vessels and circumferentially surrounded them (Figure 4, C and D). In addition, Y5R was detectable in NB cells penetrating the blood vessel wall and endothelium (Figure 4, E-G), as well as in those located in the vessel lumen (Figure $4 \mathrm{H}$ ). The analysis of staining intensities confirmed elevated Y5R expression in the cells directly surrounding blood vessels compared with those distant from the vasculature (1.9-fold increase in staining intensity, $P<0.001)$. This pattern of immunostaining suggests a 
preferential Y5R expression in angioinvasive tumor cells, which is in agreement with the elevated serum NPY levels seen in patients with metastatic NBs. Interestingly, strong Y5R immunostaining was also observed in the intratumoral vascular endothelial cells (Figure 4, D-H).

\section{Identification of Disseminating Tumor Cells in an Animal Model of NB by High Expression of Y5R and NPY}

To confirm that $\mathrm{Y} 5 \mathrm{R}$ expression is associated with an angioinvasive NB cell phenotype, we performed similar expression analyses in samples derived from TH-MYCN mice, which serve as a model of undifferentiated NB. ${ }^{36}$ This approach allowed for a direct comparison of primary tumors and their corresponding metastases that developed during disease progression (Figure 5, A-D). Interestingly, although NPY immunostaining was observed in most NB cells in the human samples, high expression of both NPY and Y5R was limited to a specific cell population in TH-MYCN mice. In primary TH-MYCN tumors, both NPY and Y5R were expressed at high levels in cells surrounding blood vessels and those apparently entering the circulation. Quantitative analysis of staining intensities revealed a 2.2-fold increase in NPY expression levels and 1.9-fold increase in Y5R expression in cells with an apparent angioinvasive phenotype compared with the cells distant from vessels $(P<0.001$ for both comparisons) (Figure 5, E and G-I). Strikingly, all NB cells in the corresponding distant metastases to various organs, including liver, ovary, and kidney, were highly positive for NPY and Y5R (Figure 5, F and J). This uniformly positive immunostaining for both NPY and Y5R was particularly apparent in small metastatic lesions contiguous with blood vessels. Together, these data from human samples and the mouse model identify the preferential expression of Y5R and NPY in angioinvasive and disseminating NB cells, strongly implying an association of this expression profile with a metastatic phenotype.

\section{Uniform Expression of $Y 2 R$ in Undifferentiated NB Cells}

Next, we analyzed the clinical and mouse model samples for $\mathrm{Y} 2 \mathrm{R}$ expression. In contrast to the selective pattern of $\mathrm{Y} 5 \mathrm{R}$ expression, $\mathrm{Y} 2 \mathrm{R}$ was more widely expressed in NB cells. Y2R mRNA was detectable in all neuroblastic tumors, and all NB and GNB tissues were Y2R immunopositive. Although no correlations between Y2R expression levels, as measured by RT-PCR and immunohistochemistry, and tested prognostic factors were found, extensive Y2R immunostaining was observed in undifferentiated cells, which were uniformly $\mathrm{Y} 2 \mathrm{R}$ positive at both the membrane and cytoplasmic levels (Figure 6A). In contrast, only 20\% to $30 \%$ of maturing ganglion cells were Y2R positive (Figure 6B), whereas mature ganglion cells in GNBs and GNs were Y2R negative (data not shown). Y2R immunostaining was also detectable in endothelial cells of all tumor types (Figure 6B). Similar to human NBs, the tumor cells from undifferentiated NBs arising in TH-MYCN mice were $100 \%$ positive for $\mathrm{Y} 2 \mathrm{R}$, confirming its universal expression in this tumor subtype (Figure 6C).

In summary, expression patterns of NPY and its receptors observed in human NBs and confirmed in an animal model of its aggressive form correlated with experimentally established functions of NPY and its cognate receptors. ${ }^{16,22,35}$ Thus, our current data provide strong clinical support for previously defined molecular mechanisms by which elevated NPY levels contribute to NB progression, dissemination, and poor clinical outcome. ${ }^{16,22,35}$

\section{Discussion}

Previous studies performed on small patient cohorts indicated high NPY synthesis in NB tissues and its elevated plasma levels; however, the expression of NPY receptors or possible clinical significance of NPY or receptor expression patterns was not directly assessed. ${ }^{28-30,40,41}$ Herein, we present results of a comprehensive study that evaluated tumor mRNA and protein levels of NPY and its receptors along with its serum concentrations in matching samples from 87 patients with neuroblastic tumors. This approach allowed us to determine, for the first time, correlations between NPY system expression in tumor tissue, systemic NPY levels, and clinical outcomes.

Although NPY is used as a marker of sympathetic differentiation, its mRNA levels were higher in undifferentiated or poorly differentiated NBs compared with differentiating tumors. ${ }^{42}$ This phenomenon is consistent with the cholinergic switch that occurs in differentiating NBs, which lose their adrenergic properties and acquire a cholinergic phenotype. ${ }^{43}$ This has been reported on retinoic acid-induced differentiation in vitro and in NB patients. ${ }^{42,43}$ Because NPY is expressed in adrenergic neurons, its synthesis is downregulated in NB cells by retinoic acid and, as shown here, in differentiating NBs. ${ }^{13,42}$

The high NPY mRNA level in undifferentiated or poorly differentiated NBs was in agreement with its elevated serum levels in patients with these tumors, indicating release of the peptide to the circulation. ${ }^{34}$ Such NPY release from undifferentiated NB cells has been directly proven in vitro. ${ }^{16,22,35}$ Consistent with this hypothesis, marked amounts of NPY were detectable within the extracellular microenvironment of undifferentiated, Schwannian stroma-poor NBs, whereas in differentiating NBs the peptide was primarily intracellular.

Aside from clinical features of NB, the amount of circulating NPY in patients may also depend on overall tumor burden. Although primary tumor volumes were not available to test this possibility directly, our current findings and those from previous reports strongly indicate that it is the tumor phenotype per se that is the major determinant of NPY release from NB tumors. ${ }^{16,22,35}$ For example, NPY release from the undifferentiated NB cells in vitro varied between cell lines, 

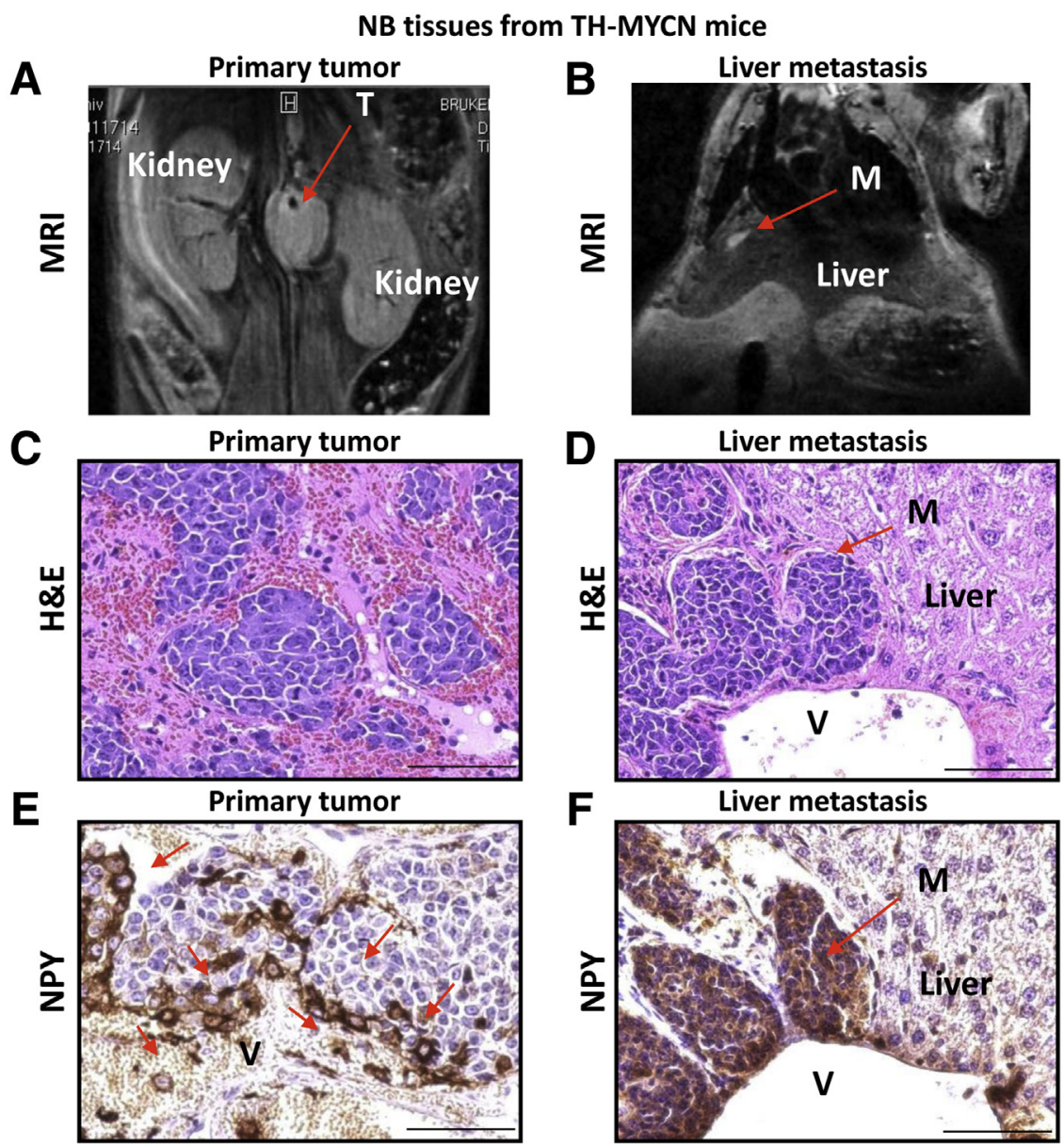

Figure 5 High neuropeptide $Y$ (NPY) and Y5 receptor ( $\mathrm{Y} 5 \mathrm{R})$ immunoreactivity marks invasive neuroblastoma (NB) cells in TH-MYCN mice. A and B: Representative magnetic resonance image (MRI) of a primary tumor ( $\mathrm{T}$ ) and liver metastasis (M) in the TH-MYCN mouse model of NB. C and D: Hematoxylin and eosin (H\&E) staining of the primary tumor and liver metastases derived from TH-MYCN mice. E: NPY immunostaining in TH-MYCN tumors. NPY-positive cells within the primary tumor (red arrows) accumulate around blood vessels (V) and in the blood stream. F: Representative image of NPY immunostaining in liver metastasis derived from a TH-MYCN mouse. All cells within the lesion are highly positive for NPY. G-I: Y5R immunostaining in primary tumors arising in TH-MYCN mice. Groups of highly Y5Rpositive NB cells (red arrows) are detectable around the vessels $(\mathbf{G})$, penetrating the vessel wall

G

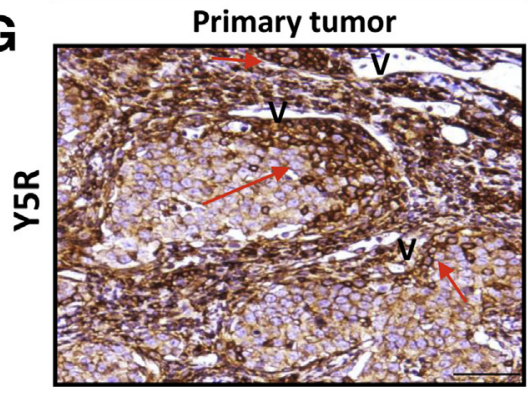

I

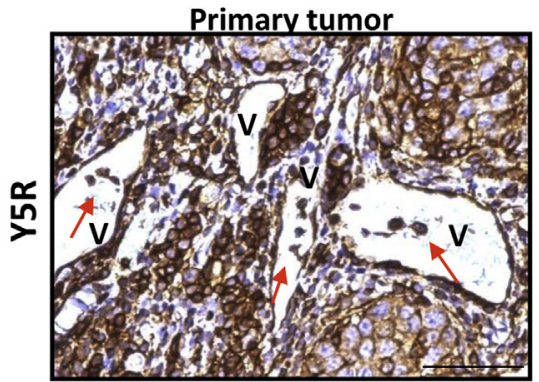

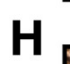

Primary tumor
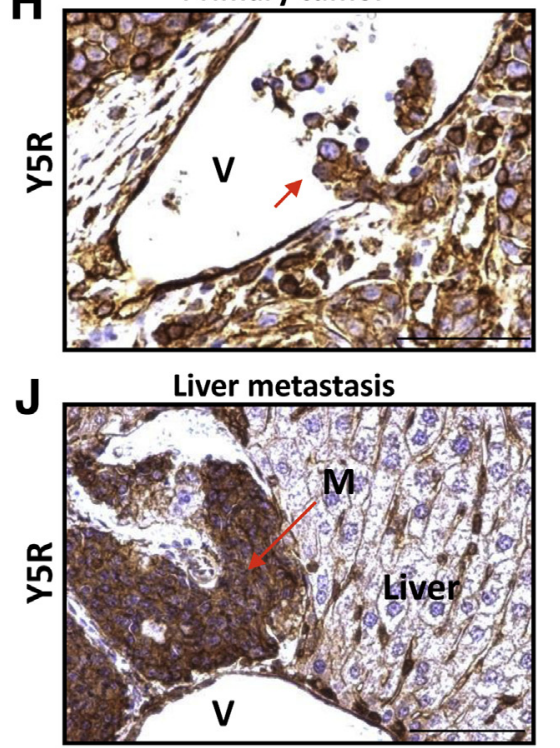

(H) and in the vessel lumen (I). J: Representative image of $Y 5 R$ immunostaining in liver metastasis derived from a TH-MYCN mouse. All cells within the lesion are positive for Y5R. The images are shown at various magnification levels to highlight the patterns of immunostaining seen within tumor tissue. Scale bar $=50 \mu \mathrm{m}(\mathbf{C}-\mathbf{J})$. decreased upon NPY siRNA treatment, and was particularly high in chemoresistant cells with elevated NPY mRNA levels. ${ }^{22,35}$ Consistent with these data, we found that serum NPY concentrations positively correlated with its tumor mRNA levels, suggesting that tumors with elevated peptide expression release a high amount of NPY into the circulation.
Although previous studies did not find such correlations, this may be associated with our cohort being rich in patients with undifferentiated NBs, where the associations between mRNA and serum levels are most prevalent. ${ }^{29}$ Furthermore, NPY release can also be dependent on other features of tumor cells, such as the level of their differentiation, because 

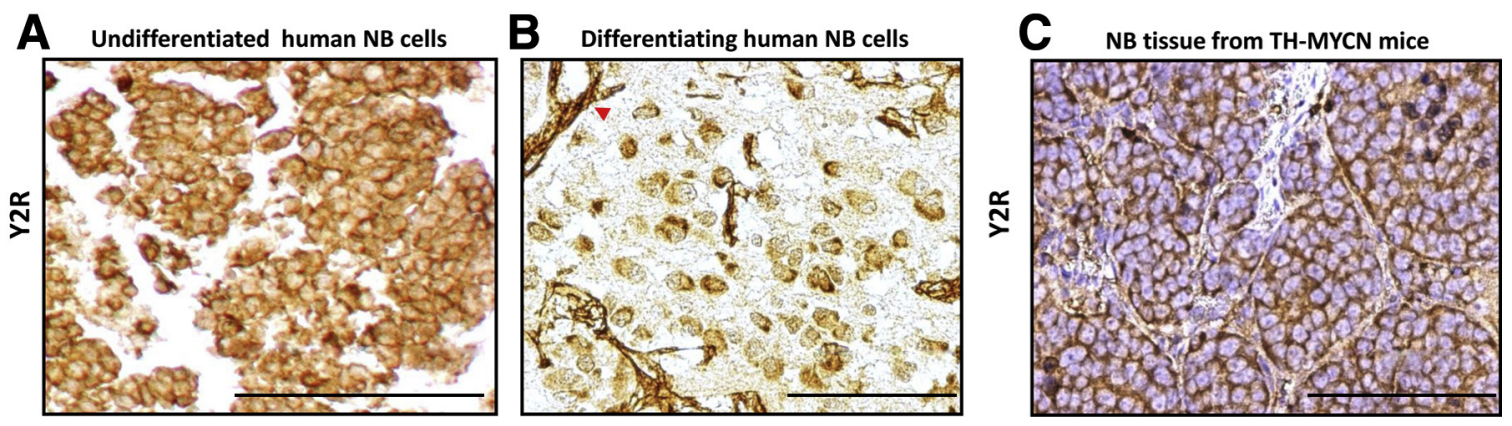

Figure 6 Y2 receptor (Y2R) is universally expressed in undifferentiated neuroblastoma (NB) cells. A and B: Representative images of Y2R immunostaining in undifferentiated (A) and differentiating (B) human NB tissues. The red arrowhead indicates Y2R-positive endothelial cells. C: Y2R immunostaining in a tumor developing in a TH-MYCN mouse. Scale bar $=100 \mu \mathrm{m}(\mathbf{A}-\mathbf{C})$.

undifferentiated NB cells release neurotransmitters in an uncontrolled manner. ${ }^{44}$ Moreover, the undifferentiated or poorly differentiated tumors are more cellular and therefore may release more NPY than stroma-rich differentiating tumors of comparable size. ${ }^{4}$ Finally, the secretion of the peptide may be further modified by the tumor microenvironment (eg, the presence of Schwannian stroma), which suppresses the aggressive phenotype and vascularization of $\mathrm{NB} .{ }^{45}$ In line with this evidence, our analyses indicated multiple correlations of high serum NPY levels with adverse tumor features that are independent of tumor size, such as a low level of differentiation, unfavorable histologic features, diploidy, and high MKI. Because NPY actions are mediated by surface receptors, the ability of NB tumors to release the peptide is essential for its functionality. Consequently, an elevated systemic level of NPY rather than its expression in the tumor tissue was strongly associated with unfavorable prognosis in NB patients. Interestingly, we have shown a similar variability in NPY release in Ewing sarcoma patients, whereas others reported it in pheochromocytoma patients. ${ }^{34}$

The uniform positive immunostaining of undifferentiated NB cells for NPY and Y2R is consistent with their constitutive mRNA expression and crucial role of the NPY/Y2R autocrine loop in maintaining NB cell proliferation and tumor vascularization. ${ }^{16,22}$ Similarly, the focal pattern of $\mathrm{Y} 5 \mathrm{R}$ immunostaining is in agreement with its inducible expression in $\mathrm{NB} .{ }^{35}$ We have previously found that $\mathrm{Y} 5 \mathrm{R}$ expression is induced by hypoxia, a known prometastatic factor. $^{23,35}$ In line with this observation, strong Y5R immunostaining was observed in angioinvasive NB cells that accumulated around blood vessels. Importantly, similar perivascular localization has been found for hypoxiainducible factor (Hif)- $2 \alpha$-positive NB cells that exhibit an aggressive, undifferentiated phenotype. ${ }^{46,47}$ Because Hif- $2 \alpha$ is one of the master regulators of the hypoxic response and Y5R expression is up-regulated by hypoxia, the associations between these two factors in the subpopulation of invasive NB cells deserves further investigation. ${ }^{23,46}$

The specific pattern of Y5R expression in angioinvasive NB cells was confirmed in the TH-MYCN animal model, where high NPY and Y5R immunoreactivity was observed in disseminating NB cells within primary tumors and in all metastatic NB cells in distant organs. Collectively, these data establish high expression of Y5R and NPY as a marker for a distinct population of angioinvasive and metastatic NB cells. This concept is in agreement with the increased serum NPY levels seen in NB patients with metastases and further supports our hypothesis that high circulating NPY observed in patients with metastatic NBs reflects a specific tumor phenotype rather than merely high tumor burden. Interestingly, in previous reports and in our present study, elevated serum NPY levels were also observed in patients with stage $4 \mathrm{~S} \mathrm{NB} .{ }^{29}$ Despite their unique biological features, stage $4 \mathrm{~S}$ tumors present with metastases at the time of diagnosis, which was when NPY was measured in our study. Thus, high NPY release appears to be a compelling marker of active metastatic disease. Altogether our results warrant further investigations into the prometastatic activity of the NPY/Y5R autocrine loop as the potential mechanism underlying the adverse effect of elevated NPY on NB patient survival. ${ }^{16,22}$

The growth-promoting and metastatic actions of NPY can also be partially associated with its angiogenic activity. ${ }^{21}$ Although $\mathrm{Y} 2 \mathrm{R}$ is the main angiogenic receptor of NPY, endothelial cells in NB tumors were strongly immunopositive for both $\mathrm{Y} 2 \mathrm{R}$ and $\mathrm{Y} 5 \mathrm{R} .{ }^{48,49}$ This expression pattern is consistent with the role of $Y 5 R$ in enhancing $Y 2 R$ mediated endothelial cell proliferation and migration. ${ }^{20}$ Although we have reported that a Y2R antagonist reduced vascularization in NB and Ewing sarcoma xenografts, whereas a Y5R antagonist alone did not, it is plausible that the combination of both antagonists may have an augmented antiangiogenic effect. ${ }^{22,23,35}$

Consistent with our findings in NB patients, associations of elevated systemic NPY with disease dissemination were previously suggested for other NPY-rich tumors. ${ }^{32,34}$ In pheochromocytoma, plasma NPY levels were higher in patients with malignant tumors compared with those with benign lesions. ${ }^{32}$ However, this marked increase in systemic NPY was limited to patients with metastases present at the time of NPY measurement but not those who developed metastases later in the disease. Although these results 
seemed to contradict earlier findings that indicated a decreased percentage of tumors with detectable NPY mRNA among malignant pheochromocytomas, the latter study was performed on a small number of cases and did not indicate the time of metastasis development. ${ }^{33}$ Moreover, neither of these studies took into consideration the localization of primary tumors, even though NPY is preferentially expressed in adrenal tumors, whereas extra-adrenal pheochromocytomas are NPY negative. ${ }^{31-33}$ The extra-adrenal tumors constitute $10 \%$ of pheochromocytomas but are more frequently malignant than adrenal tumors. ${ }^{50,51}$ Thus, these NPY-negative extra-adrenal tumors may be overrepresented among patients with metastatic disease. If true, elevated systemic NPY levels may actually be a marker of an active metastatic process in patients with adrenal pheochromocytomas. This hypothesis is in agreement with our previous report that suggested elevated serum NPY levels in patients with metastatic Ewing sarcoma and high serum levels of NPY in patients with stage 4 and stage $4 \mathrm{~S} \mathrm{NB}{ }^{34}$ Although a previous study performed on a limited number of samples indicated a lack of detectable NPY mRNA in stage 4 infantile NBs, our study did not confirm this finding. ${ }^{28}$ This discrepancy could be associated with differences in methods because previously used in situ hybridization may not be capable of detecting homogenous, diffuse mRNA expression. ${ }^{28}$

Overall, the clinical and preclinical findings presented herein provide further support for targeting the NPY axis in NB therapy and identify patients with metastatic disease as a subpopulation that may benefit the most from such treatments. These therapies may include $\mathrm{Y} 2 \mathrm{R}$ and $\mathrm{Y} 5 \mathrm{R}$ antagonists, which are already available and have been tested in animal studies and clinical trials for other disorders. ${ }^{52}$ In addition, surface expression of NPY receptors offers the possibility of targeted delivery of radiotherapeutics and chemotherapeutics using their ligands. ${ }^{53}$ Given the heterogeneity of NB, targeting factors associated with the basic neurobiology of these tumors, such as NPY, is a promising therapeutic approach for a broad patient population. The feasibility of such biology-driven strategies has been demonstrated by improvements in NB outcome and management achieved through treatment with retinoic acid and anti-ganglioside 2 antibody, as well as radionuclide delivery via the catecholamine analog metaiodobenzylguanidine. ${ }^{1,54}$

Because of its strong association with unfavorable disease phenotype, elevated systemic NPY levels may also serve as a novel, minimally invasive biomarker for NB risk stratification. High serum NPY levels correlated with 5 adverse prognostic factors, including high risk based on the INRG system. ${ }^{2}$ Consequently, patients with increased serum NPY levels had significantly worse OS and EFS, which is in agreement with early reports indicating an association of high plasma NPY concentrations with poor outcome of NB..$^{29,30}$ Although some patients with elevated systemic NPY levels had a favorable disease outcome, none of the known NB prognostic factors, including the INRG system, are completely accurate. ${ }^{2}$ Conversely, our finding that a highly statistically significant association exists between elevated systemic NPY levels and worse survival in patients without $M Y C N$ amplification has important clinical implications because these patients are more difficult to stratify than those with $M Y C N$ amplification. Notably, the trend toward worse survival in patients with high NPY levels was also observed in the subgroup without $M Y C N$ amplification presenting with low- or intermediate-risk disease, suggesting that NPY measurement may improve stratification of this group over the existing INRG system, if this potential correlation is confirmed in a larger cohort of patients. Thus, on the basis of our data, NPY is a serum biomarker of high-risk disease that can be easily measured and may improve the standard of care for patients with non $M Y C N$-amplified tumors. Interestingly, a subgroup of aggressive NBs without $M Y C N$ amplification is known to carry a variety of other genomic aberrations in primary tumors and corresponding metastases, including gain of chromosome 7, which contains the locus of the NPY gene. ${ }^{55}$ Thus, it is important to determine the association between these genetic aberrations, as well as other known features of this NB subset (eg, high expression of $M Y C$ oncogene), and NPY system expression. ${ }^{56}$

Because of its strong correlations with advanced stage of the disease, high serum NPY levels did not achieve statistical significance as an independent prognostic factor in multivariate analysis. Of note, in the same analysis for EFS, MYCN amplification, the well-established adverse prognostic factor for $\mathrm{NB}$, was also not statistically significant. Hence, the above results do not rule out the clinical utility of serum NPY, particularly given its strong association with worse survival in patients with $M Y C N$ nonamplified tumors and accessibility of the clinical material for its measurement.

In contrast to previous reports on pheochromocytoma, we found a correlation of high NPY release at diagnosis with future relapse in NB patients. ${ }^{32}$ Other studies have found an association of high NPY content in neuroblasts infiltrating bone marrow with early relapse and poor clinical outcome of NB. ${ }^{57}$ These findings support our previous data implicating the NPY/Y5R axis as a prosurvival pathway involved in NB chemoresistance. ${ }^{35}$ Because NPY expression and release are up-regulated in chemoresistant NB cells, plasma NPY levels may be further elevated during relapse. ${ }^{35}$ Such a secondary increase in NPY levels during recurrence may explain the presence of patients with initially normal NPY levels in the subpopulation with future relapse. Collectively, these data support the potential utility of systemic NPY levels in monitoring NB progression, as previously suggested for NB and pheochromocytoma. ${ }^{41,58}$ In pilot studies, elevated plasma NPY concentrations normalized after successful treatment, while lack of a posttreatment decrease in circulating NPY levels was associated with disease relapse and fatal outcome. ${ }^{29,30,41,58}$ Importantly, in contrast to current monitoring procedures, the measurement of blood NPY 
is a simple, minimally invasive analytical test that does not require access to tumor tissue. ${ }^{1}$

Collectively, our current findings describe the strong association between elevated systemic NPY levels and adverse clinical phenotype of NB, supporting the crucial role of the NPY axis in NB growth and progression that is implicated by our previous experimental data and validating this pathway as a relevant therapeutic target. ${ }^{16,22,35}$ The observed correlation between high serum NPY and metastases, as well as increased Y5R expression in angioinvasive NB cells, implicates the NPY/Y5R axis as a metastatic pathway in $\mathrm{NB}$ and identifies patients with disseminated disease as a candidate population for anti-NPY therapy. Moreover, the association of high systemic NPY levels with disease relapse supports its clinical utility as a minimally invasive biomarker for monitoring NB progression. On the basis of our data, further large-scale validation trials are warranted.

\section{Acknowledgments}

MRI was performed in the Georgetown-Lombardi Comprehensive Cancer Center's Preclinical Imaging Research Laboratory, and the statistical analyses were partially performed by the Georgetown-Lombardi Comprehensive Cancer Center Biostatistics \& Bioinformatics Shared Resources.

\section{References}

1. Maris JM: Recent advances in neuroblastoma. N Engl J Med 2010, 362:2202-2211

2. Cohn SL, Pearson AD, London WB, Monclair T, Ambros PF, Brodeur GM, Faldum A, Hero B, Iehara T, Machin D, Mosseri V, Simon T, Garaventa A, Castel V, Matthay KK: The International Neuroblastoma Risk Group (INRG) classification system: an INRG Task Force report. J Clin Oncol 2009, 27:289-297

3. Lonergan GJ, Schwab CM, Suarez ES, Carlson CL: Neuroblastoma, ganglioneuroblastoma, and ganglioneuroma: radiologic-pathologic correlation. Radiographics 2002, 22:911-934

4. Shimada H, Ambros IM, Dehner LP, Hata J, Joshi VV, Roald B, Stram DO, Gerbing RB, Lukens JN, Matthay KK, Castleberry RP: The International Neuroblastoma Pathology Classification (the Shimada system). Cancer 1999, 86:364-372

5. Vermeulen J, De Preter K, Mestdagh P, Laureys G, Speleman F, Vandesompele J: Predicting outcomes for children with neuroblastoma. Discov Med 2010, 10:29-36

6. Asgharzadeh S, Pique-Regi R, Sposto R, Wang H, Yang Y, Shimada H, Matthay K, Buckley J, Ortega A, Seeger RC: Prognostic significance of gene expression profiles of metastatic neuroblastomas lacking MYCN gene amplification. J Natl Cancer Inst 2006, 98: $1193-1203$

7. Fardin P, Barla A, Mosci S, Rosasco L, Verri A, Versteeg R, Caron HN, Molenaar JJ, Ora I, Eva A, Puppo M, Varesio L: A biology-driven approach identifies the hypoxia gene signature as a predictor of the outcome of neuroblastoma patients. Mol Cancer 2010, 9:185

8. Garcia I, Mayol G, Rios J, Domenech G, Cheung NK, Oberthuer A, Fischer M, Maris JM, Brodeur GM, Hero B, Rodriguez E, Sunol M, Galvan P, de Torres C, Mora J, Lavarino C: A three-gene expression signature model for risk stratification of patients with neuroblastoma. Clin Cancer Res 2012, 18:2012-2023
9. Van Roy N, De Preter K, Hoebeeck J, Van Maerken T, Pattyn F, Mestdagh P, Vermeulen J, Vandesompele J, Speleman F: The emerging molecular pathogenesis of neuroblastoma: implications for improved risk assessment and targeted therapy. Genome Med 2009, 1:74

10. Granchi D, Garaventa A, Amato I, Paolucci P, Baldini N: Plasma levels of receptor activator of nuclear factor-kappaB ligand and osteoprotegerin in patients with neuroblastoma. Int J Cancer 2006, 119:146-151

11. Haupt R, Garaventa A, Gambini C, Parodi S, Cangemi G, Casale F, Viscardi E, Bianchi M, Prete A, Jenkner A, Luksch R, Di Cataldo A, Favre C, D'Angelo P, Zanazzo GA, Arcamone G, Izzi GC, Gigliotti AR, Pastore G, De Bernardi B: Improved survival of children with neuroblastoma between 1979 and 2005: a report of the Italian Neuroblastoma Registry. J Clin Oncol 2010, 28:2331-2338

12. Ikematsu S, Nakagawara A, Nakamura Y, Ohira M, Shinjo M, Kishida S, Kadomatsu K: Plasma midkine level is a prognostic factor for human neuroblastoma. Cancer Sci 2008, 99:2070-2074

13. Zukowska-Grojec Z: Neuropeptide Y. A novel sympathetic stress hormone and more. Ann N Y Acad Sci 1995, 771:219-233

14. Hansel DE, Eipper BA, Ronnett GV: Neuropeptide Y functions as a neuroproliferative factor. Nature 2001, 410:940-944

15. Pons J, Kitlinska J, Ji H, Lee EW, Zukowska Z: Mitogenic actions of neuropeptide $\mathrm{Y}$ in vascular smooth muscle cells: synergetic interactions with the beta-adrenergic system. Can J Physiol Pharmacol 2003, 81:177-185

16. Kitlinska J, Abe K, Kuo L, Pons J, Yu M, Li L, Tilan J, Everhart L, Lee EW, Zukowska Z, Toretsky JA: Differential effects of neuropeptide $\mathrm{Y}$ on the growth and vascularization of neural crest-derived tumors. Cancer Res 2005, 65:1719-1728

17. Son MY, Kim MJ, Yu K, Koo DB, Cho YS: Involvement of neuropeptide $\mathrm{Y}$ and its $\mathrm{Y} 1$ and $\mathrm{Y} 5$ receptors in maintaining self-renewal and proliferation of human embryonic stem cells. J Cell Mol Med 2011, 15:152-165

18. Han R, Kitlinska JB, Munday WR, Gallicano GI, Zukowska Z: Stress hormone epinephrine enhances adipogenesis in murine embryonic stem cells by up-regulating the neuropeptide Y system. PLoS One 2012, 7:e36609

19. Lee NJ, Doyle KL, Sainsbury A, Enriquez RF, Hort YJ, Riepler SJ, Baldock PA, Herzog H: Critical role for Y1 receptors in mesenchymal progenitor cell differentiation and osteoblast activity. J Bone Miner Res 2010, 25:1736-1747

20. Movafagh S, Hobson JP, Spiegel S, Kleinman HK, Zukowska Z: Neuropeptide $\mathrm{Y}$ induces migration, proliferation, and tube formation of endothelial cells bimodally via Y1, Y2, and Y5 receptors. FASEB J 2006, 20:1924-1926

21. Lee EW, Michalkiewicz M, Kitlinska J, Kalezic I, Switalska H, Yoo P, Sangkharat A, Ji H, Li L, Michalkiewicz T, Ljubisavljevic M, Johansson H, Grant DS, Zukowska Z: Neuropeptide Y induces ischemic angiogenesis and restores function of ischemic skeletal muscles. J Clin Invest 2003, 111:1853-1862

22. Lu C, Everhart L, Tilan J, Kuo L, Sun CC, Munivenkatappa RB, Jonsson-Rylander AC, Sun J, Kuan-Celarier A, Li L, Abe K, Zukowska Z, Toretsky JA, Kitlinska J: Neuropeptide Y and its Y2 receptor: potential targets in neuroblastoma therapy. Oncogene 2010, 29:5630-5642

23. Tilan JU, Lu C, Galli S, Izycka-Swieszewska E, Earnest JP, Shabbir A, Everhart LM, Wang S, Martin S, Horton M, Mahajan A, Christian D, O'Neill A, Wang H, Zhuang T, Czarnecka M, Johnson MD, Toretsky JA, Kitlinska J: Hypoxia shifts activity of neuropeptide Y in Ewing sarcoma from growth-inhibitory to growthpromoting effects. Oncotarget 2013, 4:2487-2501

24. Magni P, Motta M: Expression of neuropeptide Y receptors in human prostate cancer cells. Ann Oncol 2001, 12 Suppl 2:S27-S29

25. Medeiros PJ, Al-Khazraji BK, Novielli NM, Postovit LM, Chambers AF, Jackson DN: Neuropeptide Y stimulates proliferation and migration in the 4T1 breast cancer cell line. Int J Cancer 2012, 131:276-286 
26. Ruscica M, Dozio E, Motta M, Magni P: Modulatory actions of neuropeptide $\mathrm{Y}$ on prostate cancer growth: role of MAP kinase/ERK 1/2 activation. Adv Exp Med Biol 2007, 604:96-100

27. Ueda K, Tatsuguchi A, Saichi N, Toyama A, Tamura K, Furihata M, Takata R, Akamatsu S, Igarashi M, Nakayama M, Sato TA, Ogawa O, Fujioka T, Shuin T, Nakamura Y, Nakagawa H: Plasma low-molecular-weight proteome profiling identified neuropeptide-Y as a prostate cancer biomarker polypeptide. J Proteome Res 2013, 12:4497-4506

28. Cohen PS, Cooper MJ, Helman LJ, Thiele CJ, Seeger RC, Israel MA: Neuropeptide Y expression in the developing adrenal gland and in childhood neuroblastoma tumors. Cancer Res 1990, 50:6055-6061

29. Dotsch J, Christiansen H, Hanze J, Lampert F, Rascher W: Plasma neuropeptide $\mathrm{Y}$ of children with neuroblastoma in relation to stage, age and prognosis, and tissue neuropeptide Y. Regul Pept 1998, 75$76: 185-190$

30. Kogner P, Bjork O, Theodorsson E: Plasma neuropeptide Y in healthy children: influence of age, anaesthesia and the establishment of an ageadjusted reference interval. Acta Paediatr 1994, 83:423-427

31. de SSP, Denker J, Bravo EL, Graham RM: Production, characterization, and expression of neuropeptide $\mathrm{Y}$ by human pheochromocytoma. J Clin Invest 1995, 96:2503-2509

32. Grouzmann E, Gicquel C, Plouin PF, Schlumberger M, Comoy E, Bohuon C: Neuropeptide Y and neuron-specific enolase levels in benign and malignant pheochromocytomas. Cancer 1990, 66: $1833-1835$

33. Helman LJ, Cohen PS, Averbuch SD, Cooper MJ, Keiser HR, Israel MA: Neuropeptide $\mathrm{Y}$ expression distinguishes malignant from benign pheochromocytoma. J Clin Oncol 1989, 7:1720-1725

34. Tilan JU, Krailo M, Barkauskas DA, Galli S, Mtaweh H, Long J, Wang $\mathrm{H}$, Hawkins $\mathrm{K}$, Lu C, Jeha D, Izycka-Swieszewska E, Lawlor ER, Toretsky JA, Kitlinska JB: Systemic levels of neuropeptide $\mathrm{Y}$ and dipeptidyl peptidase activity in patients with Ewing sarcoma-Associations with tumor phenotype and survival. Cancer 2015, 121:697-707

35. Czarnecka M, Trinh E, Lu C, Kuan-Celarier A, Galli S, Hong SH, Tilan JU, Talisman N, Izycka-Swieszewska E, Tsuei J, Yang C, Martin S, Horton M, Christian D, Everhart L, Maheswaran I, Kitlinska J: Neuropeptide Y receptor Y5 as an inducible pro-survival factor in neuroblastoma: implications for tumor chemoresistance. Oncogene 2015, 34:3131-3143

36. Weiss WA, Aldape K, Mohapatra G, Feuerstein BG, Bishop JM: Targeted expression of MYCN causes neuroblastoma in transgenic mice. EMBO J 1997, 16:2985-2995

37. Hong SH, Tilan JU, Galli S, Izycka-Swieszewska E, Polk T, Horton M, Mahajan A, Christian D, Jenkins S, Acree R, Connors K, Ledo P, Lu C, Lee YC, Rodriguez O, Toretsky JA, Albanese C, Kitlinska J: High neuropeptide Y release associates with Ewing sarcoma bone dissemination - in vivo model of site-specific metastases. Oncotarget 2015, 6:7151-7165

38. Kaplan E, Meier P: Non-parametric estimation from incomplete observations. J Am Stat Assoc 1958, 53:457-481

39. Peto R, Pike MC, Armitage P, Breslow NE, Cox DR, Howard SV, Mantel N, McPherson K, Peto J, Smith PG: Design and analysis of randomized clinical trials requiring prolonged observation of each patient. II. analysis and examples. Br J Cancer 1977, 35:1-39

40. Grouzmann E, Comoy E, Bohuon C: Plasma neuropeptide Y concentrations in patients with neuroendocrine tumors. J Clin Endocrinol Metab 1989, 68:808-813

41. Rascher W, Kremens B, Wagner S, Feth F, Hunneman DH, Lang RE: Serial measurements of neuropeptide $\mathrm{Y}$ in plasma for monitoring neuroblastoma in children. J Pediatr 1993, 122:914-916

42. Edsjo A, Nilsson H, Vandesompele J, Karlsson J, Pattyn F, Culp LA, Speleman F, Pahlman S: Neuroblastoma cells with overexpressed MYCN retain their capacity to undergo neuronal differentiation. Lab Invest 2004, 84:406-417
43. Bourdeaut F, Janoueix-Lerosey I, Lucchesi C, Paris R, Ribeiro A, de Pontual L, Amiel J, Lyonnet S, Pierron G, Michon J, Peuchmaur M, Delattre O: Cholinergic switch associated with morphological differentiation in neuroblastoma. J Pathol 2009, 219:463-472

44. Itoh T, Omori K: Biosynthesis and storage of catecholamines in pheochromocytoma and neuroblastoma cells. J Lab Clin Med 1973, $81: 889-896$

45. Liu S, Tian Y, Chlenski A, Yang Q, Zage P, Salwen HR, Crawford SE, Cohn SL: Cross-talk between Schwann cells and neuroblasts influences the biology of neuroblastoma xenografts. Am J Pathol 2005, 166:891-900

46. Holmquist-Mengelbier L, Fredlund E, Lofstedt T, Noguera R, Navarro S, Nilsson H, Pietras A, Vallon-Christersson J, Borg A, Gradin K, Poellinger L, Pahlman S: Recruitment of HIF-1alpha and HIF-2alpha to common target genes is differentially regulated in neuroblastoma: HIF-2alpha promotes an aggressive phenotype. Cancer Cell 2006, 10:413-423

47. Pietras A, Gisselsson D, Ora I, Noguera R, Beckman S, Navarro S, Pahlman S: High levels of HIF-2alpha highlight an immature neural crest-like neuroblastoma cell cohort located in a perivascular niche. J Pathol 2008, 214:482-488

48. Ekstrand AJ, Cao R, Bjorndahl M, Nystrom S, Jonsson-Rylander AC, Hassani H, Hallberg B, Nordlander M, Cao Y: Deletion of neuropeptide Y (NPY) 2 receptor in mice results in blockage of NPYinduced angiogenesis and delayed wound healing. Proc Natl Acad Sci U S A 2003, 100:6033-6038

49. Lee EW, Grant DS, Movafagh S, Zukowska Z: Impaired angiogenesis in neuropeptide Y (NPY)-Y2 receptor knockout mice. Peptides 2003, 24:99-106

50. Linnoila RI, Keiser HR, Steinberg SM, Lack EE: Histopathology of benign versus malignant sympathoadrenal paragangliomas: clinicopathologic study of 120 cases including unusual histologic features. Hum Pathol 1990, 21:1168-1180

51. Tischler AS: Pheochromocytoma and extra-adrenal paraganglioma: updates. Arch Pathol Lab Med 2008, 132:1272-1284

52. Walther C, Morl K, Beck-Sickinger AG: Neuropeptide Y receptors: ligand binding and trafficking suggest novel approaches in drug development. J Pept Sci 2011, 17:233-246

53. Bohme D, Beck-Sickinger AG: Drug delivery and release systems for targeted tumor therapy. J Pept Sci 2015, 21:186-200

54. Yanik GA, Villablanca JG, Maris JM, Weiss B, Groshen S, Marachelian A, Park JR, Tsao-Wei D, Hawkins R, Shulkin BL, Jackson H, Goodarzian F, Shimada H, Courtier J, Hutchinson R, Haas-Koga D, Hasenauer CB, Czarnecki S, Katzenstein HM, Matthay KK: 131I-metaiodobenzylguanidine with intensive chemotherapy and autologous stem cell transplantation for high-risk neuroblastoma. A new approaches to neuroblastoma therapy (NANT) phase II study. Biol Blood Marrow Transplant 2015, 21:673-681

55. Cobrinik D, Ostrovnaya I, Hassimi M, Tickoo SK, Cheung IY, Cheung NK: Recurrent pre-existing and acquired DNA copy number alterations, including focal TERT gains, in neuroblastoma central nervous system metastases. Genes Chromosomes Cancer 2013, 52: $1150-1166$

56. Wang LL, Teshiba R, Ikegaki N, Tang XX, Naranjo A, London WB, Hogarty MD, Gastier-Foster JM, Look AT, Park JR, Maris JM, Cohn SL, Seeger RC, Asgharzadeh S, Shimada H: Augmented expression of MYC and/or MYCN protein defines highly aggressive MYC-driven neuroblastoma: a Children's Oncology Group study. $\mathrm{Br}$ J Cancer 2015, 113:57-63

57. Nowicki M, Ostalska-Nowicka D, Miskowiak B: Prognostic value of stage IV neuroblastoma metastatic immunophenotype in the bone marrow: preliminary report. J Clin Pathol 2006, 59:150-152

58. Grouzmann E, Fathi M, Gillet M, de Torrente A, Cavadas C, Brunner H, Buclin T: Disappearance rate of catecholamines, total metanephrines, and neuropeptide $\mathrm{Y}$ from the plasma of patients after resection of pheochromocytoma. Clin Chem 2001, 47:1075-1082 